International Journal of Childhood, Counselling and Special Education (CCSE)

\title{
The Level of Social and Academic Adjustment among Syrian Refugee Students in Jordan and its Relation with Underachievement students
}

\author{
Kholoud Imhammad Meqbel Al-Mseidin, ${ }^{1}$
}

Department of Psychological $\mathbb{E}$ Educational Counselling, Ministry of Education, Jordan

Received: $30^{\text {th }}$ Aug 2020 Revised: $11^{\text {th }}$ Sept 2020 Accepted: $21^{\text {th }}$ Sept $2020 \quad$ DOI: https://doi.org/10.31559/CCSE2020.1.2.1

Abstract: Research on the level of social and academic adjustment and the ties between both Syrian refugee students in Jordan is still insufficient due to the lack of research and interest among academics and researchers. This is happening even though the rise of refugees has impacted students from the Syrian Refugee Education Center SREC in Jordan in the last five years. Therefore, the current study examines the connection between social adjustment and academic adjustment among Syrian refugee students in SREC in Jordan. A total of 108 SREC-contained students from one school were studied. The results of the study showed that social adjustment is poor $(52 \%)$ and academic adjustment is small (67\%). Furthermore, there is a statistically important negative association $(-0.522)$ between the overall social adaptation and the total academic transition. In this report, the findings, shortcomings, and recommendations were also addressed.

Keywords: Social Adjustment; Academic Adjustment; Refugee Students; Underachievement students.

1 Corresponding author

Kholoud Imhammad Meqbel Al-Mseidin

Ph.D. in Educational and Psychological Counselling, Department of Psychological \& Educational Counselling, Ministry of Education, Amman, Jordan

E-mail: me4youjl@hotmail.com 
International Journal of Childhood, Counselling, \& Special Education (CCSE), Volume1, Issue: 2, December: 2020, pp.100-111

\section{Introduction}

Since 2011, the number of Syrian refugees in Jordan was increased; This is due to the relatively peaceful existence of Jordan in the Arab region. Many studies, such as Gharaebah, show that (2014), Syrian refugee students in Jordan are faced social and academic adjustment problems. Furthermore, many studies have illustrated that social and academic adjustment problems are the major reasons for underachievement among students (Ashour, et al., 2010; Lazarus \& Folkman, 1984; Lee $\&$ Chen, 2000; Olimat, et al., 2013).

Moreover, Olimat et al. (2013); Tomul and Savasci (2013) confirms that student academic performance is connected to many issues such as socio-economic characteristics, student disparity and student capital.

In this context, the impact on academic and social performance among students is expressed in the results of the educational process on academic and social aspects.

The studies of Al-Mseidin, Omar-Fauzee, \& Kaur (2017b); Ashour, et al. (2010); Lee and Chen (2000); Olimat, Saaida, and Alzyadat (2013) were shown when students suffer from the low level of social and academic adjustment, and this problem leads to be underachievers at the next educational stages. Besides, the researchers explained that the levels of social and academic adjustment are related to academic performance.

However, the extent of social adjustment and academic adjustment among Syrian refugee students in Jordan is not discussed. Furthermore the relationship between social and academic transition and underperformance. Thus, the aims of this paper are to (i) investigate the level of social and academic adjustment among Syrian refugee students; (ii) examine the relationship between the level of social and academic adjustment and underachievement.

\section{Social Adjustment}

According to Cook (1990), Social adjustment refers to the nature of the relationship between student and his family, friends and school staff. Moreover, social adjustment at school means full compliance with the rules and procedures at the school (Cook, 1990).

There are four factors help students to increase the low level of social adjustment: the first one is personal and psychological needs 
International Journal of Childhood, Counselling, \& Special Education (CCSE), Volume1, Issue: 2, December: 2020, pp.100-111

should be satiated among students, the second one is knowing and accepting the self, the third one is the individual's abilities and skills to achieve the basic needs, and the last one is the ability to flexible response to external influences (Habit, 2003).

Further, Levine and Levine (1996) identified four aspects of social adjustment are: social integration, competence, social responsibility, and personal development. Furthermore, they found that the most difficult aspect was social integration for primary and secondary school students. The teachers at primary and high schools contribute a major role in the adjustment the students (Levine \& Levine, 1996).

According to Polloway, et al. (1994), students spend most of their day in school, and the crucial element in social adjustment is considered their behaviour in school. Furthermore, the school is contributed to develop the formative relationships with peers and adults. As that, the learning tasks of students and the others around them can be bothered by unsuitable behaviour at school (Polloway, et al., 1994).

\section{Academic Adjustment}

Academic adjustment defines as "having a positive attitude toward setting academic goals, completing academic requirements, the effectiveness of the efforts to meet academic goals, and being successful in the academic environment" (Baker \& Syrik, 1999). As pointed out by Baker \& Syrik (1999) that academic adjustment refers to a clear sense to aims and learning motivation and meet academic demands are considered an essential and necessary to achieve a high level of academic adjustment.

As pointed out by Gerdes and Mallinckrodt (1994), they outline the concept of academic adjustment to four aspects: learning motivation, satisfaction from the academic environment, a sense of purposefulness and action to comply with academic demands. Moreover, they identified that the fourth aspects require to develop some of the practical skills such as learning skills, writing and summarising, thinking and memorising, submitting homework and schoolwork, time management and exams. (Gerdes \& Mallinckrodt, 1994; Zeidner, 1992).

According to Russell and Petrie (1992), there are three primary aspects of academic adjustment: the 
International Journal of Childhood, Counselling, \& Special Education (CCSE), Volume1, Issue: 2, December: 2020, pp.100-111

first one is forecasting for academic adjustment this aspect involve to three basic factors: society factors such as family variables and social support, academic factors such as study skills and academic motivation, and personality factors such as self-esteem and locus of control. The second primary aspect is educational outcomes related to academic adjustment; this related to the three essential factors in the first aspect. The last one is the Intervention, applying and treatment; here, we should treat the low level of academic adjustment through counselling programs and psychological interventions to improve the low level of academic adjustment. These interventions and programs are carried out through individual counselling, group counselling and school programs by the counsellor (Russell and Petrie, 1992).

\section{Research Methodology}

\section{The Population and Sampling of the Study}

This research is a cross-sectional study to study the relationship between the students of social and academic adjustment and the underperformance of the Syrian refugee.
The population of the present study was all Underachievement Syrian refugee students from Syrian Refugees Education Centres in Jordan. Furthermore, a sample of 108 Syrian refugee students were chosen none randomly from two schools (Hend Bint Omyyah for female and Talhah Bin ObedEllah for male) in Amman City in Jordan. Next table illustrates the demographics of sampling.

Table 1. The demographics of sampling

\begin{tabular}{llll}
\hline Grades & Male & Female & Total \\
\hline Sixth grade & 13 & 13 & 26 \\
$\begin{array}{l}\text { Seventh } \\
\text { grade }\end{array}$ & 13 & 14 & 27 \\
Eighth grade & 14 & 15 & 29 \\
Ninth grade & 13 & 13 & 26 \\
Total & 53 & 55 & 108 \\
\hline
\end{tabular}

\section{Instrumentations}

The researcher used two instruments to perform the current study: Social Adjustment Scale and Academic Adjustment Scale.

Social Adjustment Scale: Fudah (2008) produced a scale of 33 items. The size of the study was also divided into three dimensions: the teenagerschool environment, the teenagefamily relationship and the teenagegroup relationship. The scale has been calculated on a Likert scale of 
International Journal of Childhood, Counselling, \& Special Education (CCSE), Volume1, Issue: 2, December: 2020, pp.100-111

five points: always, sometimes, occasionally, never seldom.

According to Fudah (2008), the minimum score of scale is 33 , and the maximum is 165 . Furthermore, the final results of the scale are into three results categories: Low $=$ under 77, Medium $=77-121$, And High= more 122 .

Al-Mseidin et al., (2017a) extracted the reliability to social adjustment scale through the results of Cronbach's alpha, where 54 students were received the scale from the same school. Next table illustrates the results of Cronbach's alpha with an acceptable value (0.79).

Table 2. The Cronbach's Alpha for the social adjustment

Cronbach'sCronbach's Alpha Based $\mathrm{Nu}$. of Alpha on Standardised Items Items

$\begin{array}{lll}0.79 & 0.82 & 33\end{array}$

Academic Adjustment Scale: the Academic Adjustment Scale was developed from Henry Barrow's scale (1949) by Nassar (2010), where Sahawneh (1989) translated the scale from Henry Barrow's scale to Arabic version to suit the Jordanian environment. The total items of the scale were 43 items. The scale was also graded on a 5-point Likert scale: mostly, sometimes, sometimes, seldom, never. The scale was divided into five dimensions: curriculum adaptation, ambition level and maturity targets, personal effectiveness in preparing and timeconsuming, academic abilities, and personal connections with professors and students. The minimum scale score is 43 , with a maximum score of 215. In addition, the final scale outcomes are divided into 3 groups of results: Low $=$ under 100 , Medium $=100-157$, and High $=$ more 157.

Al-Mseidin et al., (2017a) extracted the reliability to academic adjustment scale through using the results of Cronbach's alpha, where 54 -students were received the scale from the same school. Next table illustrates the results of Cronbach's alpha with an acceptable value (0.80).

Table 3. The Cronbach's Alpha for the academic adjustment

\begin{tabular}{ccc}
\hline $\begin{array}{c}\text { Cronbach's } \\
\text { Alpha }\end{array}$ & $\begin{array}{c}\text { Cronbach's Alpha Based } \\
\text { on Standardised Items }\end{array}$ & $\begin{array}{c}\text { Nu. of } \\
\text { Items }\end{array}$ \\
\hline 0.80 & 0.78 & 43 \\
\hline
\end{tabular}

\section{Procedure}

The researchers have chosen two schools that have Syrian Refugees Education Centres randomly in Amman city (Hend Bint Omyyah and Talhah Bin ObedEllah) to 
International Journal of Childhood, Counselling, \& Special Education (CCSE), Volume1, Issue: 2, December: 2020, pp.100-111

participate in the present study. Then, the researchers obtained approval from these schools to conduct the present study.

Furthermore, the researchers explained to students the objectives of the present study. Moreover, they provided the instructions to fill out the scales. Moreover, the students were informed who do not want to participate for any reasons were free to opt-out from the study by the researchers. In addition, the scales need 15-minutes to complete.

\section{Data Analysis}

The objective of this study was I to explore the relationship between Syrian students' social adjustment and under-performance (ii) to explore the relationship between Syrian students at Amman Region, Jordan. The data were analyzed using the percentage of responses and Spearman correlation for this reason.

\section{Result}

The Level of Social and Academic

\section{Adjustment}

The results of the general evaluation of the level of social adjustment were as a follow the high level (15\%), medium level (33\%) and low $(52 \%)$, as shown in the next Figure:

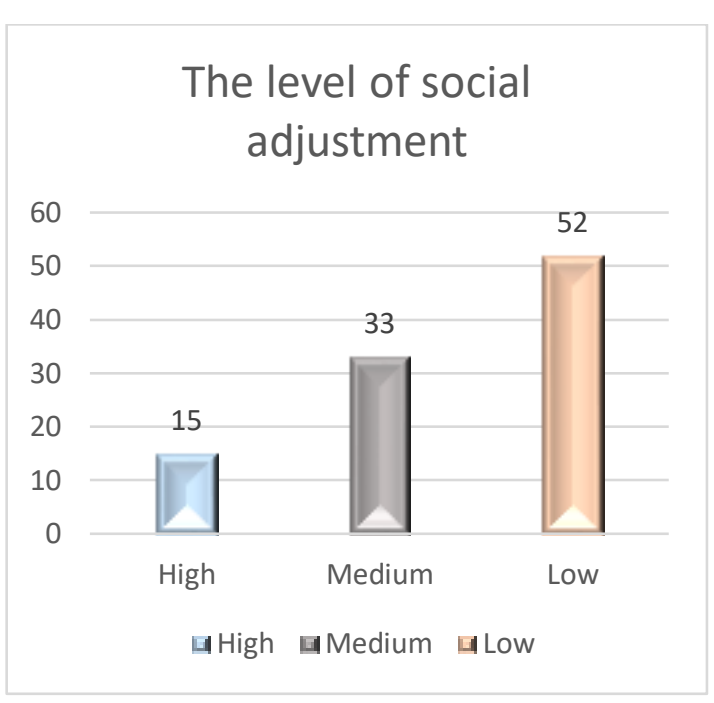

Figure 1. The results of a general evaluation of the level of social adjustment.

The results of the general evaluation of the level of academic adjustment were as a follow: the high level (9\%), medium level (24\%) and low $(67 \%)$, as shown in the next Figure:

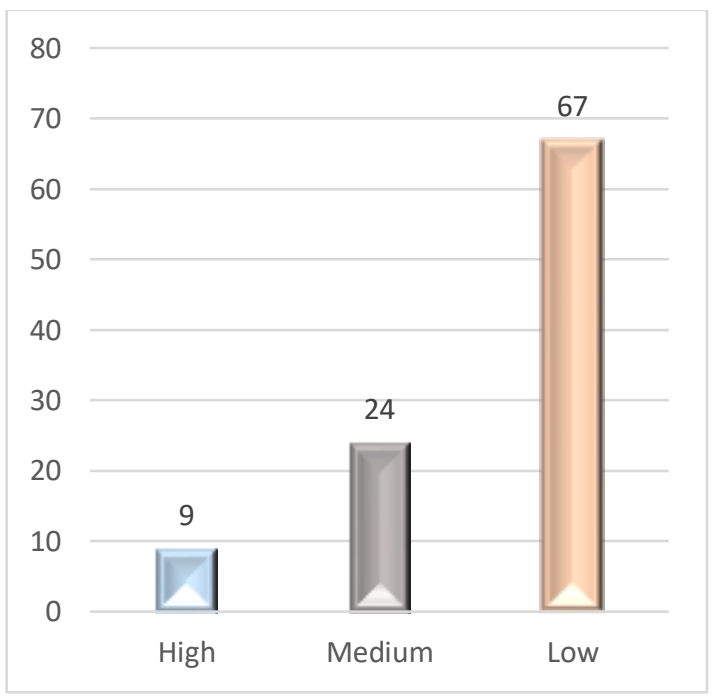

Figure 2. The results of the general evaluation of the level of academic adjustment. 
International Journal of Childhood, Counselling, \& Special Education (CCSE), Volume1, Issue: 2, December: 2020, pp.100-111

The Comparison based on levels of social adjustment and underachievement students

To evaluate the relationship between the level of social adjustments and underachievement students, the researchers used Spearman correlation. A strong negative correlation was found between the social scores of underachievement students (Spearman rho coefficient $=-0.522$, $\mathrm{p}<0.001)$, i.e. decrease in social adjustment with the reduction of underachievement.

Table 4. The correlation coefficient between social adjustment and underachievement students.

Spearman's rho social overall score P-value (2tailed)

Correlation

Coefficient

\begin{tabular}{lll}
\hline $\begin{array}{c}\text { Underachievem } \\
\text { ent }\end{array}$ & $-.522^{* *}$ & $<0.001$ \\
\hline
\end{tabular}

The Comparison based on levels of academic adjustment and underachievement students

To evaluate the relationship between the level of academic adjustments and underachievement students, the researchers used Spearman correlation. A strong negative correlation was found between the social scores of underachievement students
(Spearman rho coefficient $=-0.564$, $\mathrm{p}<0.001)$, i.e. decrease in academic adjustment with the decline in underachievement.

Table 5. The correlation coefficient between academic adjustment and underachievement students.

\begin{tabular}{lll}
\hline Spearman's rho & $\begin{array}{l}\text { Academic } \\
\text { overall score }\end{array}$ & $\begin{array}{l}\text { P-value (2- } \\
\text { tailed) }\end{array}$ \\
& $\begin{array}{l}\text { Correlation } \\
\text { Coefficient }\end{array}$ & \\
&
\end{tabular}

underachievement $\quad 0.564^{* *} \quad<0.001$

\section{Discussions}

This section discusses the results of the present study related to social adjustment and academic adjustment. Further, the correlation between social adjustment and underachievement students, additionally, between academic adjustment and underachievement students through analyses of the results.

Next table shows the percentage of the level of social adjustment among Syrian refugee students in Jordan.

Table 6. The level of social adjustment among Syrian refugee students in Jordan

\begin{tabular}{lccc}
\hline The level & High & Medium & Low \\
\hline Percentage & $15 \%$ & $33 \%$ & $52 \%$ \\
\hline
\end{tabular}


International Journal of Childhood, Counselling, \& Special Education (CCSE), Volume1, Issue: 2, December: 2020, pp.100-111

The results show that the level of social adjustment among Syrian Refugee Students in Jordan is low level (52\%), Medium level (33\%) and High level (15\%). This result conforms to the previous studies (e.g. Deveci, 2012; Gharaebah, 2014; Hanoun, 2001) where was shown a low or medium level of social adjustment among students. The results of the current study were because of lack of psychological and counselling support at school that contains a Syrian Refugee Education Centre (SREC), it is supposed at this centres that provide a type of counselling program which it helps refugee students to overcome and improve the low level of social adjustment. Other reason which refers to different cultures between Syrian and Jordanian students this reason leads to decrease the level of social adjustment where the different cultures which include thinking, customs and traditions cause the low level of social adjustment among Syrian refugee students.

The last reason which could affect the low level of social adjustment, this reason relates to the challenges that could face the refugee students such as life's pressures and adaptive impediments, this challenges will affect to decrease the level of social adjustment among Syrian refugee students. Next table illustrates the percentage of academic adjustment among Syrian refugee students.

Table 7. The level of academic adjustment.

\begin{tabular}{lccc}
\hline The level & High & Medium & Low \\
\hline Percentage & $9 \%$ & $24 \%$ & $67 \%$ \\
\hline
\end{tabular}

There are a lack of studies that addressed academic adjustment among Syrian refugee students, because of that, the researchers dependent on the studies that are near to the present study.

The results show a low level of academic adjustment among students of Syrian refugees (67\%). This finding is consistent with previous studies (Abu Leil, 2011; Nassar, 2010).

In the current study, the researchers attribute the reasons for the low level of academic adjustment because of adaptive pressures and problems which Syrian refugee students were faced because of the different environment in which they live. Besides, the researchers confirm that this problem was found because the lack of psychological and counselling support at school that contains a Syrian Refugee Education Centre (SREC), it is supposed at this centres that provide a type of counselling program which it helps refugee students to overcome and 
International Journal of Childhood, Counselling, \& Special Education (CCSE), Volume1, Issue: 2, December: 2020, pp.100-111

improve the low level of academic adjustment.

We believed that Syrian refugee students were faced a lot of problems because of the Syrian war, which led to leaving their country and looking for a safe country. Therefore, it is reasonable to have a drop in the level of academic adjustment among Syrian refugee students. This reason is considered a major reason for the low level of academic adjustment.

The results of the relationship between social and academic adjustment in the table (3), based on levels of social and academic adjustment, show that the total score of social adjustment and the overall score of academic adjustment among Syrian refugee students in Jordan have a strong negative association with a coefficient of social and academic adjustment (-.564).

Family instability is responsible for the negative relationship between social adjustment and academic adjustment because the family resides violently in another country. This aspect is then negatively expressed in his thought and actions in the academic field. This limits her adaptability, which is negatively reflected in her academic achievement.
In addition, a low level of social skills affects trust between students, leading to underperformance among students. A low level of social skills thus prevents students from gaining the confidence and encouragement that impacts on academic performance.

Accordingly, the findings of this research on a negative relationship between social adjustment and academic adjustment indicate that the reasons for the negative association between social and academic adjustment are as follows: (i) poor social capacities (ii) family dysfunction.

\section{Limitation}

The main issue faced in this study is that more schools could not be surveyed because of logistics limitations. Therefore, the number of schools surveyed which contain Syrian Refugee Education Centre SREC were limited to just one school in Amman City, Jordan. Another study should focus on more schools in order to generalise the findings.

\section{Suggestion and Future Investigation}

The researcher proposed that a supervisory committee be set up with UNHCR in the Jordanian Ministry of Education to monitor and assess 
International Journal of Childhood, Counselling, \& Special Education (CCSE), Volume1, Issue: 2, December: 2020, pp.100-111

the level of adjustment in society and academia among Syrian refugee students, as well as increase the low levels of social and academic adjustment through therapy and interventions. Qualitative research and experimental studies should, therefore, be conducted over a period of time to achieve better results among Syrian refugee students in the SREC. Increase in the levels of social and academic adjustment should be tackled through experimental studies that explore approaches based on primary school therapy theories to solve this issue.

Moreover, the current survey only included students of Syrian refugees from one SREC, while another analysis might concentrate on multi-SREC to generalize results.

\section{References}

Abu Lil, A. (2010). Level of Social Adjustment and Academic Adjustment of Arab and Jewish students at Haifa University. (Unpublished master thesis, Yarmouk University).

Al-Mseidin, K. I., Omar-Fauzee, M. S., \& Kaur, A. (2017a). The Relationship between Social and Academic Adjustment among Secondary Female Students in
Jordan. European Journal of Education Studies, 3(2), 333-346

Al-Mseidin, K. I., Omar-Fauzee, M. S., \& Kaur, A. (2017b). The effectiveness of cognitive behaviour therapy on social adjustment among low achievement female students in Jordan. International Journal of Advanced Education and Research, 2(4), 216-222.

Ashour, M., Obaid, K., \& Abdul Karim, M. (2010). The reasons for failure of students in the southern provinces in the final exam for a sixth-grade science for the academic year 2007-2008 in chemistry. Journal of Basic Education College, 64, 131166.

Baker, R.W., \& Siryk, B. (1999). Student Adaptation to College Questionnaire. Los Angeles, Ca: Western Psychological Services.

Cook, E. L. (1990). An analysis of school adjustment and extracurricular activities of lowerachieving students (Unpublished doctoral dissertation, Miami University).

Deveci, Y. (2012). Trying to understand: promoting the psychosocial well-being of separated refugee children. Journal of Social Work Practice, 26(3): 367-383, https://doi.org/10.1080/02650533.2012. 658033 
International Journal of Childhood, Counselling, \& Special Education (CCSE), Volume1, Issue: 2, December: 2020, pp.100-111

Fudah, S. (2008). The relationship between emotional intelligence and social adjustment among adolescents in light of some variables (Unpublished doctoral dissertation, Yarmouk University, Jordan).

Gharaebah, S. (2014). The level of psychological and social adjustment among the primary graders for Syrian refugees in Al-Zaatary camp (Jordan) in light of some variables (Unpublished doctoral dissertation, Yarmouk University, Jordan).

Gerdes, H. \& Malinckrodt, B. (1994). Emotional, social and academic adjustment of college students: A longitudinal study of retention. Journal of Counseling and Development, 72(3): 281 - 288, https://doi.org/10.1002/j.15566676.1994.tb00935.x

Habit, M. (2003). The foundations of the psychological individual health. Cairo: Almaktab Aljameai.

Hanoun, R. A. E. K. (2001). Anxiety and Its Influence on the Political Views of Palestinian Youngsters.

Hosin, A. A., Moore, S., \& Gaitanou, C. (2006). The relationship between psychological well-being and adjustment of both parents and children of exiled and traumatised Iraqi refugees. Journal of Muslim Mental Health, 1(2): 123. 136 , https://doi.org/10.1080/1556490060098 0616

Lazarus, R. S., Folkman, S. (1984). Stress, Appraisal and Coping. New York: Springer.

Lee, B. K., \& Chen, L. (2000). Cultural communication competence and psychological adjustment. Communication Research, 27(6): 764-787, https://doi.org/10.1177/0093650000270 06004

Levine, D. U. \& Levine, R. F. (1996). Society and education. (ERIC Document Reproduction Service No. ED 426 972)

Meyer, S., Murray, L. K., Puffer, E. S., Larsen, J., \& Bolton, P. (2013). The nature and impact of chronic stressors on refugee children in Ban Mai Nai Soi camp, Thailand. Global public health, 8(9): 1027-1047, https://doi.org/10.1080/17441692.2013. 811531

Nassar, E. (2010). The relationship between self-efficacy and academic adjustment among secondary school students in Nazareth city in light of some variables (Unpublished doctoral dissertation. Yarmouk University).

Olimat, A., Saaida, M., \& alzyadat, E. (2013). Reasons for the low level of academic achievement in English language curriculum. For secondary 
International Journal of Childhood, Counselling, \& Special Education (CCSE), Volume1, Issue: 2, December: 2020, pp.100-111

school students in public schools in Salt rod from the point of view of teachers and proposed solutions to improve the achievement level. Scientific journal of the Faculty of Education - Assiut University, 29(2): 433-468.

Polloway, Edward A., Epstein, Michael H., R. (1994). Classroom grading: A national survey of policies. Remedial and Special Education (RASE), 15(3): 162-170.

Russell, R. K., \& Petrie, T. A. (1992). Academic adjustment of college students: Assessment and counseling. in: Steven Brown, R. (Ed.) Handbook of counseling psychology. John Wiley, N.Y.

Sahawneh, R. N. (1989). The Patterns of academic adjustment among government college students (Unpublished doctoral dissertation. Yarmouk University).

Tomul, E., \& Savasci, H. S. (2012). Socioeconomic determinants of academic achievement. Educational Assessment, Evaluation and Accountability, 24(3): 175-187, https://doi.org/10.1007/s11092-012-

9149-3

Zeidner, M. (1992). Sources of academic stress: The case of first year Jewish and Arab college students in Israel. Higher Education, 24(1): 25 40, https://doi.org/10.1007/bf00138616 